\title{
Perceived Risk versus Perceived Value for Money: Assessing Online Retail Shopping Behavior among Ghanaians
}

\author{
Gideon Buernartey Boyetey ${ }^{1}$ (), Samuel Antwi ${ }^{2}$ \\ ${ }^{1}$ School of Statistics and Mathematics, Zhejiang Gongshang University, Hangzhou, China \\ ${ }^{2}$ School of Management and E-Business, Zhejiang Gongshang University, Hangzhou, China \\ Email: gideonbb@outlook.com, samantwi88@outlook.com
}

How to cite this paper: Boyetey, G. B., \& Antwi, S. (2021). Perceived Risk versus Perceived Value for Money: Assessing Online Retail Shopping Behavior among Ghanaians. iBusiness, 13, 117-143. https://doi.org/10.4236/ib.2021.133008

Received: June 29, 2021

Accepted: August 6, 2021

Published: August 9, 2021

Copyright $\odot 2021$ by author(s) and Scientific Research Publishing Inc. This work is licensed under the Creative Commons Attribution International License (CC BY 4.0).

http://creativecommons.org/licenses/by/4.0/ (c) (i) Open Access

\begin{abstract}
The online fashion market is the largest market segment in Ghana. This present study investigates what drives Ghanaian consumers to purchase fashion products online from perceived risk and perceived value for money perspectives. Moving away from the purely monetary perspective, this study operationalizes value for money to include ease of use (qualitative perspective). Findings from this study highlight the fact that the average Ghanaian e-buyer is more influenced to shop for fashion products online by their perceived value for money than by their perceived risk and this insight is relevant in boosting e-commerce transactions significantly in the economy.
\end{abstract}

\section{Keywords}

Perceived Risk Constructs, Perceived Value for Money, Intention to Purchase, Actual Purchase, Consumer Behavior

\section{Introduction}

The introduction of the internet has had a significant impact on all sectors, including the business sector. Over the past two decades, internet activities have grown steadily. As such, many businesses all over the world have incorporated the internet into their business. The internet has made it possible for companies to offer their products and brand to their customers on an online shopping platform. Historically, the traditional shopping methods require a seller, retailer, distributor, or manufacturer and a buyer or a customer to necessarily meet face-to-face before transactions could be performed.

E-commerce, also known as online shopping, has changed the face of business 
transactions in recent times. It is more convenient than the traditional shopping method (Ventre \& Kolbe, 2020). It appears that most consumers prefer to buy products online, although the traditional shopping method still exists. This is evident from past data on global e-commerce revenue. Data obtained from eMarketer (2019) shows that the value of global e-commerce sales in 2014 stood at US\$1.3 trillion, and rose to US\$2.3 trillion at the end of 2017. The revenue is expected to reach US $\$ 4.9$ trillion by the end of 2021. E-commerce activities in Ghana and Africa at large on the other hand seem to be low, although there has been some improvement in internet connectivity, and the number of smartphone users also increased over the past years. Africa is one of the emerging markets for e-commerce and in Ghana, (Statista, 2020) estimated that e-commerce revenue was US $\$ 309 \mathrm{~m}$ in 2019 , and the projected market volume shall be US $\$ 811.3 \mathrm{~m}$ by 2024 . The report further revealed that the e-commerce user penetration rate was $18.3 \%$ in 2019 and is projected to reach $31.6 \%$ in 2024 .

Although online shopping offers numerous benefits and has been a very successful business venture, customers feel reluctant in purchasing their various products on an online shopping platform due to the risks associated with online transactions. They are concerned about an unsuccessful product delivery, a variation in product quality, and privacy concerns such as credit card or debit card information leakage etc. In Ghana, Boateng et al. (2011) asserted that there had been some efforts by some commercial agencies to infuse efficiency and speed in online shopping. Despite this, Ghanaians seem to be more concerned about the risks of online transactions. Therefore, it is not surprising that Hajli (2015) posited that perceived risk associated with an online transaction is the main barrier to e-commerce or online shopping. Because buyers and sellers don't meet in person to transact in an online shopping platform, buyers face the challenge of buying goods and services from unverified e-retailers Hajli et al. (2017), hence online customers are extra careful and are also concerned with any potential risk(s) on the transaction.

Again, considering the potential benefits a customer stands to gain over the traditional retail stores, a Ghanaian consumer will factor those things as comparative pricing, time and effort spent in looking for a product, ease of use of the medium of purchase, and associated costs in procuring the product with its attendant convenience (all culminating into perceived value for money) before making an informed decision of purchasing goods online. In giving a better perspective to how consumers perceive value for money, Zeithaml (1988) suggested that efforts of e-retailers to reduce the sacrifice of consumers go a long way to enhance consumers' perception of value. This presupposes that the easier it is for customers to find and comprehend information about a particular product offering, the better their value is due to the effort and time-saving function.

Past studies (Amponsah \& Antwi, 2021; Antwi et al., 2021; Antwi \& Amponsah, 2021; Bhatti \& Ur Rehman, 2020; Cho \& Son, 2019; Peng \& Liang, 2013; Se- 
tiawan et al., 2016; Sheehan et al., 2019; Sinha \& Singh, 2017) have examined consumer behavior in an online shopping platform. However, to the best of our knowledge, it appears no or limited studies have been conducted to examine the role of perceived risk constructs and perceived value for money on consumer intention to purchase and actual purchase. We aimed to explore the effect of perceived risks and perceived value for money on shopping for fashion products online among Ghanaian consumers. We present a brief highlight of the Ghanaian fashion industry and the study conceptual framework and hypothesis development in the subsequent sections. Afterwards, we discussed the methodology and the analysis and discussion of the data collected. We ended with the study's implications and limitations.

\section{The Fashion Industry in Ghana}

The Ghanaian fashion landscape loosely consists of Ghanaian designers worldwide, small to medium scale enterprises, creative professionals, non-governmental organizations, chambers of commerce, and a few others interested in developing and establishing a flourishing Ghanaian fashion industry. Indeed, while the world is fascinated by Ghanaian culture and costume, it has had very little to show on the world stage against the Paris and American designer brands. The fashion industry in Ghana is part of the "Creative Art Industry" cliché that Ghana has coined and developed as a Ministry and also includes music, film, visual art, and handicraft sub-sectors. While this is a step in the right direction to see Ghana's fashion industry blossom, stakeholders have done little to this end. It was not until April 2019 that NGOs such as DANIDA gave this vision a boost when they launched a 5-year funded project to be acted on by the University of Ghana in collaboration with Copenhagen Business School (CBS) Denmark and Loughborough University (LU), UK. The project was christened "Advancing Creative Industries for Development in Ghana" (ACIG project).

The Fashion market is the largest segment with a market volume of US\$98.4 million (Statista, 2020). The data above also projects revenues in the next five years, i.e., 2024. The projected annual growth rate was projected at $21.3 \%$ culminating into a revenue of US\$811.3 million by 2024. Projection figures for 2019 in terms of user penetration were recorded at $18.3 \%$ and expected to hit $31.6 \%$ in 2024 (Statista, 2020). In the light of modern digital and technological trends, there promises to be massive prospects for the industry regarding access to a larger global market while cutting down on certain overhead costs and competing favorably with international brands.

\section{Conceptual Framework and Hypothesis Development}

The model (see Figure 1) was made up of four constructs: perceived risk and perceived value for money-independent variables, intention to purchase as a third explanatory mediator variable, and actual purchase as a dependent variable. The research hypotheses were derived from the conceptual framework, and 


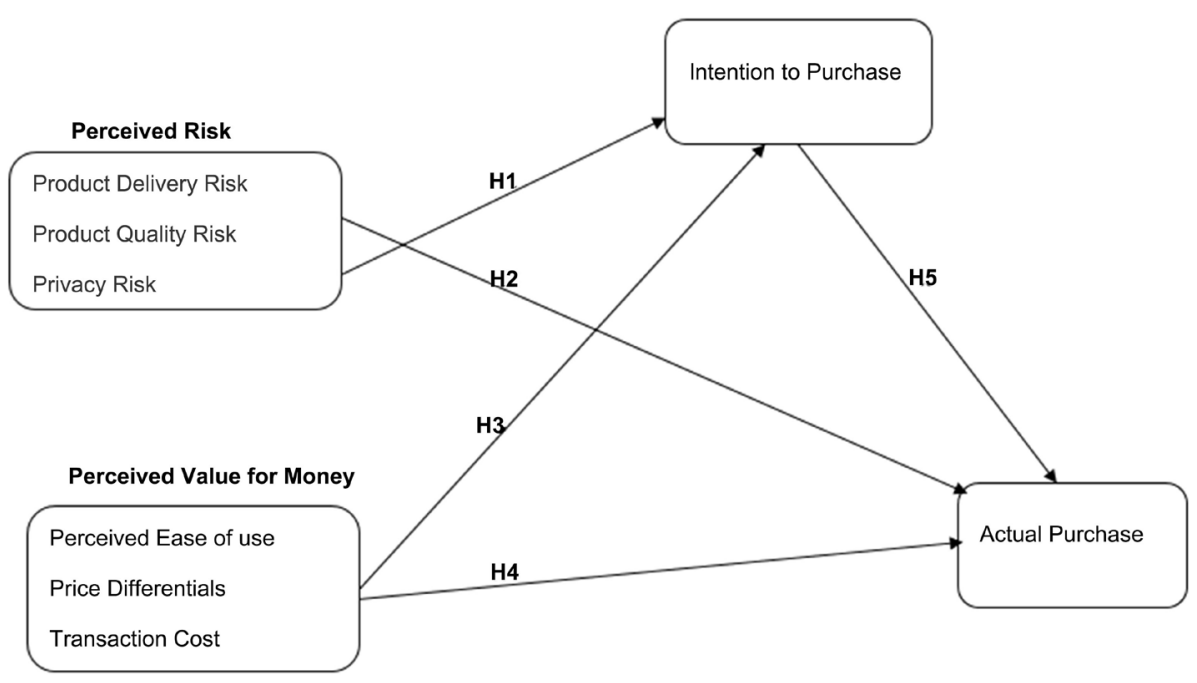

Figure 1. Conceptual framework.

empirical findings of earlier works. The earlier findings would help the researcher know whether their findings align with or contradict those works.

\subsection{Risk Perception}

Perceived risk has evolved as a major setback to the growth of online shopping. Although many e-commerce platforms have taken major steps to improve a customer shopping activity, such as secure and escrow payment systems, there are still some risks associated with online transactions or shopping on their platforms. According to Park and Tussyadiah (2017), a customer's perceived risk in online shopping is his or her belief of uncertainty associated with a transaction. The degree of uncertainty related to a particular transaction would also inform the customer whether to proceed with the transaction or not. Wagner Mainardes et al. (2019) see customer purchase intention as factors that determine online customer behavior to conclude a negotiation via the internet. According to (Lin et al., 2009), three main potential risks can be attributed to online shopping; product risk, website related risks and internet connectivity related risks. Other forms of online perceived risk include financial, social, physical, privacy, performance, delivery, psychological, and time risk (Bhatnagar \& Ghose, 2004; Forsythe et al., 2006; de Kerviler et al., 2016; Paluch \& Wunderlich, 2016). However, the perceived risk construct used in this present study were limited to product quality risk or performance risk, product delivery risk, and privacy risk.

\subsubsection{Product Delivery Risk (PDR)}

In online shopping, product delivery risk could be referred to as the possibility that a product purchased may not be delivered (Arora \& Rahul 2018). This could be due to wrong delivery, non-delivery, goods damaged or lost in transit, delivery delays, and others. Koyuncu and Bhattacharya (2004) opined that the most important of these is delayed delivery. Some online shopping platforms own a 
logistics company that handles their shipment, while other shopping platforms employ other third-party logistics companies to manage their freight. For example, Alibaba owns a logistics company, Cainiao, and relies on other logistics companies UPS, DHL and other logistics companies for the shipment of goods. On the other hand, Amazon does not own logistics companies and relies on third-party logistics companies such as UPS and DHL for goods shipment. Product delivery risk is a type of service failure on the part of an e-retailer and their associates, which is their logistics service (Liao \& Keng 2013). According to past studies (Adnan, 2014; Zaiț \& Bertea 2013), product delivery risk significantly affects purchase intention. Therefore;

H1a: Product Delivery Risk has a significant influence on Intention to Purchase;

H2a: Product Delivery Risk has a significant influence on Actual Purchase.

\subsubsection{Product Quality Risk (PQR)}

Product quality risk denotes a potential loss due to quality that fails to meet the expected goals (Chen et al., 2015; Sinha \& Singh, 2017). Thus, it measures the possibility that a fashion product(s) purchased in an online shopping platform might fail to satisfy or fulfill the consumer's reasonable expectation. The quality of a fashion product is based on the product description. Consumers in an online shopping platform may not know the exact quality of the fashion product they intend to buy until they actually buy it, receive it, and physically examine it (Omar, 2005). The online product review on a particular online store by early consumers can provide relevant information to new consumers about the nature of the product. Nonetheless, these remedies cannot confirm that the fashion product intended to be purchased will be of good quality without a physical examination by the consumer. Past studies have found out that product quality risk can influence an online consumer's intention to purchase (Kim et al., 2005; Zaiț \& Bertea, 2013). Hence;

H1b: Product Quality Risk has a significant influence on Intention to Purchase;

H2b: Product Quality Risk has a significant influence on Actual Purchase.

\subsubsection{Privacy Risk (PRR)}

Privacy risk is a plausible loss of control over one's private data (Paluch \& Wunderlich, 2016; Zendehdel et al., 2016). It is concerned with any information about a consumer maintained by an online shopping platform, including information that can be used to trace an individual identity, such as payment information, shopping history, shipping address information, and others of a similar kind. While such data in this digital age serve as a valuable resource for e-retailers in generating repeat purchase of the same or similar products, consumers bear a dilemma in giving out such data (Spake et al., 2011) due to fear of data leakage and security threats such as credit card fraud while also having an effortless experience with already saved data. Privacy thus still poses a risk and could affect 
purchase intention due to the bad experiences of others. Accordingly, people who have been a victim of privacy issues tend to have a higher perception of severity and vulnerability of online privacy risk (Chen et al., 2017) and feel themselves under threat and hence, they regularly change their password because of privacy issues (Chen et al., 2017). Previous studies have found that privacy risk could affect intention to purchase (Kim et al., 2005; Zaiț \& Bertea, 2013). Hence, we propose;

H1c: Privacy Risk has a significant influence on Intention to Purchase;

H2c: Privacy Risk has a significant influence on Actual Purchase.

\subsection{Perceived Value for Money}

Several studies have explained perceived value for money as a derivative of the concept of perceived value which is primarily used in marketing to measure the price the public (including individual consumers and firms) willingly pays for products and services (Peng \& Liang, 2013). Marketing professionals engage the concept of value perception to attract many customers irrespective of the price charged. Spiller and Ariely (2014) explain a consumer's perceived value for money as the best set of goods that the consumer's money can buy (maximum utility of purchase). Even though the best set of goods bought cannot be determined with certainty, the perceived value of money is based on the consumer's expected utility regardless of how the best settings may be. For this study, perceived value for money was conceptualized as perceived ease of use, price differentials and transaction cost. Thus, we considered money, time and convenience.

\subsubsection{Perceived Ease of Use (PEU)}

Perceived ease of use is an individual's opinion that a new technology/platform will be used with minimal effort (Davis, 1989, 1993). It could also be explained as a consumer's belief that less effort with a limited amount of resources is required to make purchases and have it delivered conveniently. Consumers will likely visit online stores and e-commerce websites they deem simple enough with an accessible and user-friendly user interface because it ultimately breeds satisfaction from the customer that positively impacts intention to purchase products online (Chiu et al., 2005). The concept has undertones of delivery of efficiency, comfort, and convenience from the online retailer to the e-consumer that could generate a comparative advantage in using the platform/website. Cha (2011) ultimately opines that, consumers will only feel convenience, efficiency, and comfort if the process of shopping online is easier in terms of product searching, easy access to websites and easy comparison of prices, etc. Research has established that Perceived Ease of Use has a significant influence on Purchase Intention (Broekhuizen \& Huizingh, 2006; Cho \& Sagynov, 2015; Gao \& Bai, 2014; Rehman et al., 2019) which subsequently leads to actual adoption of online shopping (Cho \& Son, 2019). Hence;

H3a: Perceived Ease of Use has a significant influence on Intention to Pur- 
chase;

H4a: Perceived Ease of Use has a significant influence on Actual Purchase.

\subsubsection{Price Differentials (PDF)}

Antwi (2021) defined Price as the amount a customer is required to exchange for a product. Consumers consider all these as a basis of comparison to determine the price fairness of e-retailers or online shops. Xia et al. (2004) posit that price fairness perceptions constitute an integral part of consumer price perceptions and price acceptability. Consumers use such attributes like reasonableness, acceptability, or justifiability in forming their price fairness perceptions (Bolton et al., 2003). Usually, price fairness goes a long way in telling whether an online consumer will form a good purchase intention and ultimately an actual purchase. In an economy like Ghana, where e-commerce is still in its infantile stages, consumers, aside from convenience, will consider whether they are paying justly for whatever product they wish to purchase.

Ailawadi et al. (2001) asserted that the practice of product discounting is the most widely used tactic in inducing consumers to initiate a purchase. It follows that discounting serves as a tool that adds value while offering some passive fringe benefits that induces potential buyers to buy specific products at designated time periods. E-retailers usually take advantage of festive seasons to boost their sales via discounting. Others, in trying to scale the competition and generate impressive top-line figures introduce discounting, significantly affecting consumers' purchase intention. Price differentials tend to influence a consumer purchase behavior (Antwi, 2021; Kim et al., 2012; Maia et al., 2019; Setiawan et al., 2016) and subsequently, their actual purchase (Sheehan et al., 2019). Thus;

H3b: Price Differentials have a significant influence on Intention to Purchase

H4b: Price Differentials have a significant influence on Actual Purchase

\subsubsection{Transaction Cost (TRC)}

In this present study, transaction could be defined as the extensive effort, including time and other resources expended in searching for and finding the desired product online before purchasing. Thus, transaction cost comprises of information searching cost and monitoring cost. The concept of transaction cost culled from "the Transaction cost theory" was first explained by Coase (1937) while trying to adduce reasons to why firms exist. He defined Transaction cost as the costs incurred by firms in buying and selling, such as negotiating, adapting, contracting, and monitoring the said transaction of the firm (Teo \& Yu, 2005). Transaction costs have thus been found to significantly influence consumers' preference and acceptance to buy fashion products online.

A number of studies have explored the relationship between transaction cost and customer intention to purchase. For instance Kim and Kim (2004) found out the underlisted attributes (fast delivery time, money-back guarantees, low shipping and handling charge, information on the reliability of e-retailer and access to major credit card) which made up the TRC construct as the overall 
most significant effect on the shopping behavior of consumers; consistent with findings of other authors (Wu et al., 2014; Yu \& Chen, 2018; Yuen et al., 2018). Hence;

H3c: Transaction Cost has a significant influence on Intention to Purchase;

H4c: Transaction Cost has a significant influence on Actual Purchase.

\subsection{Intention to Purchase}

Zhang et al. (2020) explain the concept as the consumers' observed attitude towards purchasing some specific products and their degree of willingness to pay and conclude the purchasing transaction. Purchase intention could thus be simplified as an extemporaneous and significant shopping tendency and shopping activity usually initiated and experienced by the consumer due to an expected utility or disutility from buying or using a particular product. Intention to purchase, thus, does not make any meaningful contribution on its own unless linked with the actual purchase or, in the context of this study, actual online shopping behavior of fashion products of Ghanaians.

Some related studies (Antwi et al., 2020; Chang et al., 2019) have applied the concept in predicting customers' purchase intention and behavior; that purchase intention leading to actual purchase directly facilitates an increase in the revenue and profitability of firms. In studying and measuring purchase intention, it is of grave importance to note those factors between purchase intention and actual purchase that prevent actual purchase. The relevance of intention to purchase products online thus becomes key in predicting online shopping activities. Studies done in the past on this subject posit that intention to purchase is likely to lead to actual purchase (Edenbrandt \& Smed, 2018; Millan \& Reynolds, 2014; Wee et al., 2014; Yoshimaru et al., 2018). Thus;

H5: Intention to Purchase has a significant influence on Actual Purchase.

\subsection{Mediation Role of Intention to Purchase}

This present study proposes that the relationship between perceived risks constructs an actual purchase, and also between perceived value for money and the actual purchase will be mediated by their intention to purchase. The mediation effect of intention to purchase has been established in some past studies (Bhatti \& Ur Rehman, 2020; Yu et al., 2021). Drawing on this previous literature, we expect a mediation effect of intention to purchase on perceived risk constructs and perceived value for money on the actual purchase. Hence, we propose the hypothesis:

H6: Intention to Purchase mediate the relationship between Perceived Risk and Perceived Value for Money on Actual Purchase.

\subsection{Actual Purchase}

Actual purchase denotes a purchase by a customer. In an online shopping perspective and from the perspective of our research, the actual purchase is the fre- 
quency or the number of times a consumer shop or buy fashion products online within a given period (Ariff et al., 2013). According to Liu et al. (2017), this behavior is affected by online consumers' intention to act, which is influenced by their attitude. Consumers may have several motives and desires, and these may be complex and unpredictable. Hence, their intention to purchase may not necessarily lead to actual purchase (Antwi et al., 2020).

Millan and Reynolds (2014) further argue that many fashion products are introduced into the market in recent times. As a result, a stronger preference and a consumer desire for fashion products' status symbolism may lead to a more frequent purchase. Hence, Actual Purchase serves as a dependent variable in this present research.

\section{Methodology}

The researchers employed a questionnaire to source data from the respondents. The questionnaire had two sections. The first section was used to solicit the respondent's demographic information. Specifically, it addressed questions relating to their gender, age, online shopping experiences, education and occupation. The other part of the research instrument aimed to solicit data concerning the hypotheses posed for the study. The concept model of this research consisted of eight variables which was measured via a 5-point Likert scale [strongly disagree (1) to strongly agree (5)]. Product quality risk consisted of four items, product delivery risk, and privacy risk all consisted of four items each. Similarly, perceived ease of use, price differentials, and transaction cost all consisted of four items. Intention to purchase and actual purchase were measured using five items each. We culled the items from past studies (Agmeka et al., 2019; Ali \& Bhasin, 2019; Cho \& Son, 2019; Lee \& Lee, 2015; Mintah, 2018; Pavlou, 2003; Rehman et al., 2019; Teo \& Yu, 2005; Ventre \& Kolbe, 2020; Verhagen et al., 2006; Wee et al., 2014).

The data was collected using convenience sampling via a web survey. The participants were Ghanaians who shop fashion products from e-commerce platforms. Specifically, the data collection was done using Google Forms, where a web link leads to the online survey. The research purpose and a link to access the survey were sent to the respondents via text message and WhatsApp Messenger. In selecting the sample size for the research, we were guided by Statista (2020) Ghana report and Cochran (1977) sampling techniques. Statista (2020) reports that the e-commerce penetration rate in Ghana stood at $18.3 \%$ in 2019 and is projected to reach $31.6 \%$ in 2024 . To reduce bias in our sample selection due to differences in years and time, we used a penetration rate of $25 \%$. Thus, a sample proportion of $25 \%$. According to Cochran (1977), using a confidence interval of $95 \%$ and a sample proportion of $25 \%$, the minimum sample size required is 288 . A total of 329 responses were received at the end of the data collection period, which lasted for a month (January 20, 2021, to March 1, 2021) which was above the minimum sample size required. The data was downloaded from Google 
Forms and exported to Microsoft Excel 2019 for coding using numbers and letters on the basis of abbreviation and sequence.

\section{Data Analysis}

The respondents' demographic information was analyzed using percentages and frequencies embedded in Statistical Package for Social sciences (SPSS version 26). Partial Least Squares Structural Equation Modelling (PLS-SEM) was used to assess the measurement and the structural model with the help of SmartPLS 3.2.9 (Ringle et al., 2015).

\subsection{Respondents' Demographic Information}

Table 1 summarizes the dynamics of the average Ghanaian e-commerce population from a sample size of 329 respondents. The age ranges of $20-30$ and $31-40$ made up an overwhelming majority $(88.8 \%)$ while females also represented the majority gender (56.8\%). On educational level, those with Bachelor's Degree formed the majority respondents with $46.8 \%$ while the private sector completes the demographic summary with a majority of $64.1 \%$ respondents.

\subsection{Measurement Model}

We examined the composite reliability, internal consistency, discriminant and convergent validity of the measurement items. Table 2 shows that all the composite

Table 1. Descriptive measurement of demographic variables $(\mathrm{N}=329)$.

\begin{tabular}{|c|c|c|c|}
\hline Variables & Items & Frequency & $\%$ \\
\hline \multirow[t]{2}{*}{ Gender } & Male & 142 & 43.2 \\
\hline & Female & 187 & 56.8 \\
\hline \multirow[t]{4}{*}{ Age } & Below 20 & 9 & 2.7 \\
\hline & $20-30$ & 145 & 44.1 \\
\hline & $31-40$ & 147 & 44.7 \\
\hline & Above 40 & 28 & 8.5 \\
\hline \multirow[t]{5}{*}{ Online Shopping Experience (years) } & Below 1 & 25 & 7.6 \\
\hline & $1-3$ & 117 & 35.6 \\
\hline & $4-6$ & 121 & 36.8 \\
\hline & $7-10$ & 52 & 15.8 \\
\hline & Above 10 & 14 & 4.3 \\
\hline \multirow[t]{5}{*}{ Level of Education } & Senior High School & 13 & 4 \\
\hline & Diploma & 53 & 16.1 \\
\hline & Degree & 154 & 46.8 \\
\hline & Masters & 97 & 29.5 \\
\hline & $\mathrm{PhD}$ & 12 & 3.6 \\
\hline \multirow[t]{2}{*}{ Occupation } & Public Sector-employed & 118 & 35.9 \\
\hline & Private Sector-employed & 211 & 64.1 \\
\hline
\end{tabular}

Note: $\mathrm{N}=$ Sample size and $\%=$ Percentage. 
Table 2. Characteristics of the construct.

\begin{tabular}{|c|c|c|c|c|}
\hline Construct & Loadings & $a$ & CR & AVE \\
\hline \multicolumn{5}{|c|}{ Product Quality Risk (PQR) } \\
\hline PQR1 & 0.729 & \multirow{5}{*}{0.851} & \multirow{5}{*}{0.891} & \multirow{5}{*}{0.622} \\
\hline PQR2 & 0.813 & & & \\
\hline PQR3 & 0.875 & & & \\
\hline PQR4 & 0.776 & & & \\
\hline PQR5 & 0.741 & & & \\
\hline \multicolumn{5}{|c|}{ Product Delivery Risk (PDR) } \\
\hline PDR1 & 0.840 & & & \\
\hline PDR2 & 0.857 & \multirow{3}{*}{0.828} & \multirow{3}{*}{0.885} & \multirow{3}{*}{0.659} \\
\hline PDR3 & 0.809 & & & \\
\hline PDR4 & 0.736 & & & \\
\hline \multicolumn{5}{|c|}{ Privacy Risk (PRR) } \\
\hline PRR1 & 0.755 & \multirow{5}{*}{0.830} & \multirow{5}{*}{0.874} & \multirow{5}{*}{0.582} \\
\hline PRR2 & 0.709 & & & \\
\hline PRR3 & 0.749 & & & \\
\hline PRR4 & 0.809 & & & \\
\hline PRR5 & 0.789 & & & \\
\hline \multicolumn{5}{|c|}{ Perceived Ease of Use (PEU) } \\
\hline PEU2 & 0.715 & & & \\
\hline PEU3 & 0.812 & \multirow{3}{*}{0.806} & \multirow{3}{*}{0.872} & \multirow{3}{*}{0.631} \\
\hline PEU4 & 0.846 & & & \\
\hline PEU5 & 0.799 & & & \\
\hline \multicolumn{5}{|c|}{ Price Differentials (PDF) } \\
\hline PDF3 & 0.832 & \multirow{3}{*}{0.826} & \multirow{3}{*}{0.896} & \multirow{3}{*}{0.742} \\
\hline PDF4 & 0.894 & & & \\
\hline PDF5 & 0.858 & & & \\
\hline \multicolumn{5}{|c|}{ Transaction Cost (TRC) } \\
\hline TRC1 & 0.778 & \multirow{4}{*}{0.784} & \multirow{4}{*}{0.860} & \multirow{4}{*}{0.607} \\
\hline TRC2 & 0.768 & & & \\
\hline TRC4 & 0.820 & & & \\
\hline TRC5 & 0.749 & & & \\
\hline Intention to Purch & & & & \\
\hline IP2 & 0.770 & & & \\
\hline IP3 & 0.742 & & & \\
\hline IP4 & 0.827 & & & \\
\hline IP5 & 0.807 & 0.839 & 0.886 & 0.608 \\
\hline IP6 & 0.750 & & & \\
\hline Actual Purchase & & & & \\
\hline AP1 & 0.794 & & & \\
\hline AP2 & 0.825 & & & \\
\hline AP3 & 0.794 & & & \\
\hline AP4 & 0.854 & & & \\
\hline AP5 & 0.802 & 0.894 & 0.919 & 0.654 \\
\hline AP6 & 0.780 & & & \\
\hline
\end{tabular}

Note: sample size $(\mathrm{N})=302, \mathrm{AVE}=$ Average Variance Extracted, $\mathrm{CR}=$ Composite Reliability, $\alpha=$ Cronbach's Alpha.

reliability and the Cronbach alpha of the constructs exceed the benchmark of 0.70 (Fornell \& Larcker, 1981; Nunnally \& Bernstein, 1994). The required threshold for measuring convergent validity for each measurement item is a value 
above 0.708 for loadings and for average variance extracted (AVE), values of 0.5 or higher (Hair et al., 2011).

Consequently, six items, IP1 (0.670), PDF1 (0.584), PDR5 (0.698), PEU1 (0.522), TRC3 (0.696) and PDF2 (0.692) were deleted from the measurement items due to the factor loading below the standardized threshold (Hair et al., 2011). Results from Table 2 showed AVE figures for all constructs was above $50 \%$; indicating an appropriate level of explanation of the variance by their corresponding indicators. Also, each of the loadings exceeded the acceptable threshold.

Again, a careful view of Table 3 shows the resultant assessment of discriminant validity via HTMT recommended by Henseler et al. (2015) as a measure of the strength of correlation among variables. Henseler et al. (2015) suggested an HTMT value below 0.9 to signify the presence of discriminant validity. The study results indicating values way below the threshold indicates the presence of good discriminant validity.

\subsection{Structural Model Assessment}

We were inspired by the appropriateness of using PLS-SEM as posited by (Ringle et al., 2015) in assessing hypothesized relationships using SmartPLS 3.2.9. This was done using the bootstrap re-sampling function (5000 re-samples) as recommended by (Hair et al., 2016). The results of hypothesized connections between constructs are shown in Table 4 and Table 5 and Figure 2. The path coefficients are standardized between -1 and +1 . While path estimates closer to 1 depict stronger forecast capacity of relationships, those farther from one (1) portray weaker relations. With the exemption of Perceived Delivery Risk to Intention to Purchase, Perceived Delivery Risk to Actual Purchase, Perceived Quality Risk to Actual Purchase, Perceived Ease of Use to Actual Purchase, and Perceived Delivery Risk to Intention to Purchase to Actual Purchase, the observation of all other coefficients show positive links between the entire constructs, although the extent of the effect varies.

The above results (Table 4) give the indication that out of the 13 hypotheses

Table 3. Heterotrait-monotrait ratio (HTMT).

\begin{tabular}{ccccccccc}
\hline Construct & PQR & PDR & PRR & PEU & PDF & TRC & IP & AP \\
\hline PQR & & & & & & & \\
PDR & 0.552 & & & & & & \\
PRR & 0.500 & 0.654 & & & & & \\
PEU & 0.324 & 0.358 & 0.532 & & & & \\
PDF & 0.193 & 0.263 & 0.488 & 0.724 & & & \\
TRC & 0.339 & 0.462 & 0.552 & 0.615 & 0.649 & & \\
IP & 0.233 & 0.246 & 0.471 & 0.647 & 0.754 & 0.571 & \\
AP & 0.142 & 0.221 & 0.439 & 0.569 & 0.774 & 0.529 & 0.879 & \\
\hline
\end{tabular}




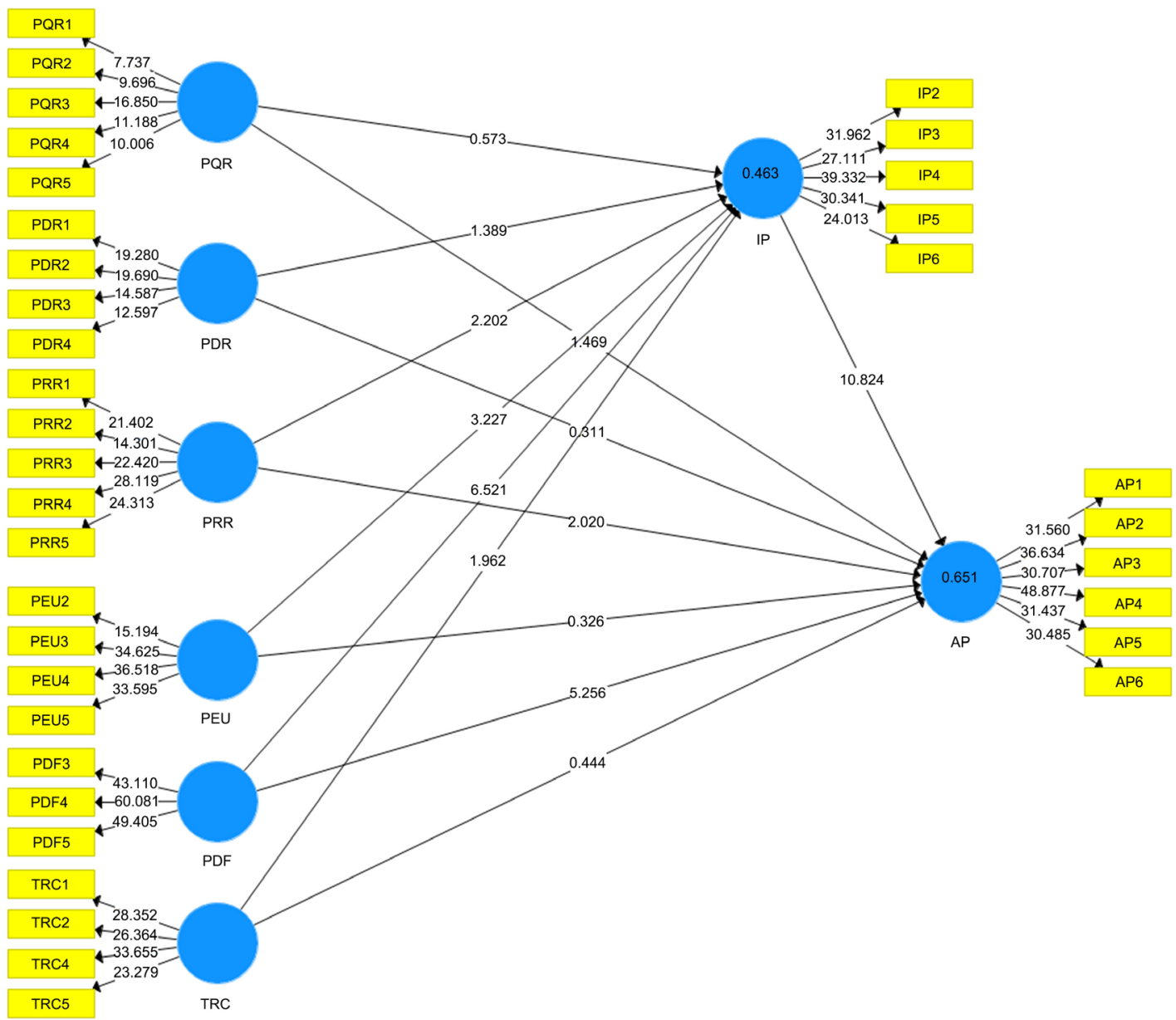

Figure 2. Structural model.

Table 4. Path coefficients of the structural model constructs.

\begin{tabular}{ccccccc}
\hline $\begin{array}{c}\text { Constructs } \\
\text { Effects }\end{array}$ & OS & SM & STDEV & $\begin{array}{c}\text { t-Value } \\
(|\mathrm{O} / \mathrm{STDEV}|)\end{array}$ & $p$-values & Conclusion \\
\hline PDR - IP & -0.067 & -0.065 & 0.048 & 1.389 & 0.165 & Not Supported \\
PQR - IP & 0.029 & 0.036 & 0.051 & 0.573 & 0.566 & Not Supported \\
PRR - IP & 0.134 & 0.135 & 0.061 & 2.202 & $0.028^{* *}$ & Supported \\
PDR - AP & -0.014 & -0.015 & 0.044 & 0.311 & 0.756 & Not Supported \\
PQR - AP & -0.066 & -0.060 & 0.045 & 1.469 & 0.142 & Not Supported \\
PRR - AP & 0.097 & 0.098 & 0.048 & 2.020 & $0.043^{* *}$ & Supported \\
PEU - IP & 0.188 & 0.189 & 0.058 & 3.227 & $0.001^{* * *}$ & Supported \\
PDF - IP & 0.410 & 0.407 & 0.063 & 6.251 & $0.000^{* * *}$ & Supported \\
TRC - IP & 0.114 & 0.114 & 0.058 & 1.962 & $0.050^{* *}$ & Supported \\
PEU - AP & -0.016 & -0.014 & 0.050 & 0.326 & 0.745 & Not Supported \\
PDF - AP & 0.280 & 0.279 & 0.053 & 5.256 & $0.000^{* * *}$ & Supported \\
TRC - AP & 0.022 & 0.023 & 0.049 & 0.444 & 0.657 & Not Supported \\
IP - AP & 0.564 & 0.563 & 0.052 & 10.824 & $0.000^{* * *}$ & Supported \\
\hline
\end{tabular}

Note: ${ }^{* * *} p$-value $<0.01 ;{ }^{* *} p$-value $<0.05$; OS $=$ Original Sample; SM $=$ Sample Mean; STDEV $=$ Standard Deviation. 
Table 5. Mediating role of intention to purchase.

\begin{tabular}{cccccc}
\hline Constructs Effects & OS & SM & STDEV & T-Value $(|\mathrm{O} / \mathrm{STDEV}|)$ & $p$-values \\
\hline PQR - IP - AP & 0.016 & 0.020 & 0.029 & 0.569 & 0.569 \\
PDR - IP - AP & -0.038 & -0.037 & 0.028 & 1.357 & 0.175 \\
PRR - IP - AP & 0.075 & 0.076 & 0.035 & 2.174 & $0.030^{\star *}$ \\
PEU - IP - AP & 0.106 & 0.106 & 0.033 & 3.233 & $0.001^{* * *}$ \\
PDF - IP - AP & 0.231 & 0.230 & 0.045 & 5.125 & $0.000^{* * *}$ \\
TRC - IP - AP & 0.064 & 0.063 & 0.032 & 1.985 & $0.047^{* *}$ \\
\hline
\end{tabular}

Note: ${ }^{* *} p$-value $<0.01 ;{ }^{* *} p$-value $<0.05 ;$ OS $=$ Original Sample; SM $=$ Sample Mean; STDEV $=$ Standard Deviation.

tested, seven are supported. For instance, the relationship between Privacy Risk (PRR) and Intention to Purchase (IP) was found to be positive and significant ( $\beta$ $=0.134 ; \mathrm{t}$-value $=2.202 ; p$-value $=0.028)$. In similar trend, the relationship between Perceived Ease of Use (PEU) and Intention to Purchase (IP) came out positive and significant $(\beta=0.188$; t-value $=3.227$; $p$-value $=0.001)$. In the same fashion, the relationship between Price Differentials (PDF) and Actual Purchase (AP) came out positive and significant $(\beta=0.280 ; \mathrm{t}$-value $=5.256$; $p$-value $=$ 0.000 ). Despite this, Product Delivery Risk (PDR) did not have a significant relationship on Intention to Purchase (IP) $(\beta=-0.067$; $\mathrm{t}$-value $=1.389$; $p$-value $=$ $0.165)$.

We also assessed the mediating role of Intention to Purchase (IP), as shown in Table 5. The results show that out of the six paths tested, four were statistically significant. Thus, the relationship between Privacy Risk (PRR) and Actual Purchase (AP) was mediated by Intention to Purchase (IP) $(\beta=0.075$; $\mathrm{t}$-value $=$ 2.174; $p$-value $=0.030)$. In the same vein, the relationship between Price Differentials (PDF) and Actual Purchase (AP) was also mediated by Intention to Purchase (IP) $(\beta=0.231$; t-value $=5.125 ; p$-value $=0.000)$. However, the relationship between Product Delivery Risk (PDR) and Actual Purchase (AP) is not mediated by Intention to Purchase $(\beta=-0.016$; $\mathrm{t}$-value $=1.357 ; p$-value $=0.175)$.

Furthermore, we examined the adjusted R-Square also known as the coefficient of determination to determine the amount of variability in the dependent constructs (such as Actual Purchase (AP) and Intention to Purchase (IP)) that is explained by the independent constructs (Perceived Risk and Perceived Value for Money dimensions). As indicated on Table 6, the adjusted R-Square value of $0.653(p=0.001)$ showed that intention to purchase, perceived risk dimensions and perceived value for money dimensions jointly explains about $65.3 \%$ of the variability in the dependent variable, actual purchase (AP). At the same time, the adjusted R-Square value of 0.467 specified that, perceived risk dimensions and perceived value for money dimensions jointly explains about $46.7 \%$ of the variability in the dependent variable, intention to purchase (IP).

On the other hand, the study employed the f-square statistics (effect size) to evaluate the predictive power of the structural model (Table 7). We assess the 
Table 6. R-square adjusted.

\begin{tabular}{ccccc}
\hline Constructs & Adjusted R-Square & $\begin{array}{c}\text { Standard Deviation } \\
(\text { STDEV })\end{array}$ & $\begin{array}{c}\text { T Statistics } \\
(\mid \mathrm{O} / \text { STDEV } \mid)\end{array}$ & $P$-values \\
\hline AP & 0.653 & 0.036 & 18.102 & $0.001^{* * *}$ \\
IP & 0.467 & 0.048 & 9.353 & $0.001^{* * *}$ \\
\hline
\end{tabular}

Note: ${ }^{* * *} p$-value $<0.01$.

Table 7. Effect size (F-Square).

\begin{tabular}{|c|c|}
\hline Constructs & Effect Size $\left(f^{2}\right)$ \\
\hline IP $\rightarrow$ AP & $0.500^{\star * * *}$ \\
\hline $\mathrm{PDF}->\mathrm{AP}$ & $0.111^{* *}$ \\
\hline PDF -> IP & $0.179^{\star * \star}$ \\
\hline PDR $->$ AP & $0.004^{*}$ \\
\hline PDR -> IP & $0.008^{*}$ \\
\hline PEU $\rightarrow$ AP & $0.004^{*}$ \\
\hline PEU -> IP & $0.042^{* *}$ \\
\hline$P Q R->A P$ & $0.012^{*}$ \\
\hline PQR -> IP & $0.005^{\star}$ \\
\hline PRR $\rightarrow$ AP & $0.019^{*}$ \\
\hline PRR -> IP & $0.022^{* *}$ \\
\hline TRC $->$ AP & $0.005^{\star}$ \\
\hline TRC -> IP & $0.019^{*}$ \\
\hline
\end{tabular}

Note: less than $0.02^{\star}=$ no effect, from 0.02 to $0.14^{\star *}=$ small/weak effect, 0.15 to $0.34^{\star * *}=$ medium effect, $0.35^{\star * * *}$ and above $=$ large effect.

effect size via Cohen (1992) guideline. Cohen (1992) considered the f-square values less than 0.02 as no effect, between 0.02 and 0.14 as weak or small effect, between 0.15 and 0.34 as medium effect, and above 0.35 as large effect. As shown in Table 7, intention to purchase (IP) has significant large effect on actual purchase (AP). Price differentials (PDF) has significant weak effect and medium effect on actual purchase (AP) and intention to purchase (IP) respectively while product delivery risk (PDR) has no significant effect on intention to purchase (IP) and actual purchase (AP). Product quality risk (PQR), and transaction cost TRC) has no significant effect on actual purchase (AP) and intention to purchase (IP) respectively. Perceived ease of use (PEU), and privacy risk (PRR) has significant weak effect on actual purchase (AP) and intention to purchase (IP) respectively.

\section{Discussion and Implications}

\subsection{Discussion}

This current study used PLS-SEM technique to validate the research model. We 
found that Product Delivery Risk (PDR) does not influence Intention to Purchase (IP) and Actual Purchase (AP) significantly. A possible explanation is that consumers are confident that the product purchased would be delivered. This is because e-retailers would like to maintain their reputation and competitiveness; hence, they will ensure that goods purchased are delivered on schedule. Besides, most online shopping platforms such as Alibaba, Amazon, and E-Bay have an escrow payment system that protects consumers from losing their money. Our findings contrast an earlier finding (Adnan, 2014; Zaiț \& Bertea, 2013).

As for Product Quality Risk (PQR), we found it has no significant effect on Intention to Purchase (IP) and Actual Purchase (AP). The finding is quite surprising as consumers would generally be cautious about the quality of a fashion product they intend to buy. It could be that Ghanaian online consumers seek the opinion of early consumers about a product they intend to purchase. These findings oppose an earlier finding (Kim et al., 2005; Zaiț \& Bertea, 2013).

Privacy Risk (PRR) is a critical predictor of Ghanaian online consumers Intention to Purchase (IP) and Actual Purchase (AP) fashion products in an online shopping platform. The results show that there is a significant positive effect of Privacy Risk (PRR) on Intention to Purchase (IP) and Actual Purchase (AP). The findings imply that when shopping for fashion products online, Ghanaian consumers are mindful of their privacy. The finding is not surprising because online shopping involves anonymity and potential opportunism. Our finding is in line with previous findings (Kim et al., 2005; Zaiț \& Bertea, 2013).

We also found that Perceived Ease of Use (PEU) has a positive and significant relationship on Ghanaian consumers' Intention to Purchase (IP) but not on their Actual Purchase (AP) of a fashion product. Indeed, considering the demographics of Ghana, especially with respect to population, a large chunk can be observed within the young ages where trends and digitization are held in high esteem. It is not surprising from our survey having an insignificant effect of ease of use on actual shopping behavior but a rather significant effect on "intention to purchase" Our finding confirms the earlier findings of (Cho \& Sagynov, 2015; Gao \& Bai, 2014; Rehman et al., 2019).

In the case of Price Differentials (PDF), we found a positive significant influence on Intention to Purchase (IP) and Actual Purchase (AP) of a fashion product. The findings imply that Ghanaian consumers consider the Price of a fashion product when making purchasing decisions and buying the product. This is because online consumers are presented with varieties of suppliers of a fashion product and may consider their prices before purchasing a product. Our findings align with these related studies (Antwi, 2021; Maia et al., 2019; Sheehan et al., 2019).

The findings further revealed that Transaction Cost (TRC) has a positive and significant influence on Intention to Purchase (IP) but not on Actual Purchase (AP) of a fashion product. The findings imply that Ghanaian consumers consider the transaction cost on a fashion product they intend to buy; however, they pay little attention to it when purchasing the product. Thus, transaction cost is 
less significant when intention to purchase has already been made. Previous studies have found out that transaction cost can influence a customer's intention to purchase (Wu et al., 2014; Yu \& Chen, 2018; Yuen et al., 2018), and hence supporting our finding.

In addition to these, we found that consumers' intention to purchase fashion products has a positive and significant influence on their actual purchase. Thus, once Ghanaian online consumers decide to buy a fashion product, they will proceed with the purchase. Our finding confirms past studies (Edenbrandt \& Smed, 2018; Wee et al., 2014; Yoshimaru et al., 2018).

To gain a more comprehensive knowledge of the research model, we performed a mediation effect of Intention to Purchase (IP). We found out the relationship between Product Quality Risk (PQR) and Actual Purchase (AP) of a fashion product by Ghanaian online consumers is not mediated by their Intention to Purchase (IP). Similarly, Intention to Purchase (IP) had no mediation effect on the relationship between Product Delivery Risk (PDR) and Actual Purchase (AP) of fashion products. Thus, the relationships between these constructs are not caused by the presence of Intention to Purchase (IP). Nonetheless, the relationship between Privacy Risk (PRR) and Actual Purchase (AP) was mediated by Intention to Purchase.

Regarding perceived value for money, the results establish that the relationship between Perceived Ease of Use (PEU) and Actual Purchase, between Price Differentials (PDF) and Actual Purchase (AP) and Transaction Cost (TRC) and Actual Purchase (AP), were all mediated by Intention to Purchase (IP). Thus, the relationship between these constructs is significantly influenced by the presence of Intention to Purchase (IP).

\subsection{Implication for Research}

This present study provides some implications for research. First, the study enriches existing literature on consumer behavior in an online shopping context by developing a well-organized concept model to explain consumer purchase mechanisms. By integrating perceived risk (product quality risk, product delivery risk, and privacy risk) and perceived value for money (perceived ease of use, price differentials, and transaction cost), this current study provides a research perspective that contributes to a deep understanding of consumer behavior. Although the research constructs have been widely investigated, relatively fewer studies have focused on investigating consumer behavior towards fashion products in an online shopping context.

This study extends research about consumer behavior in an online shopping context by assessing the mediation role of intention to purchase. Consumer intention to purchase has been used in many past studies relating to consumer behavior as a dependent variable. However, this present study employs the construct as a third explanatory mediator variable. Accordingly, this is one of the few studies that assess the mediating effect of intention to purchase in an online context. 


\subsection{Implication for Practice}

This research also provides valuable contributions that managers, shopping platform owners, digital marketers, and e-retailers may consider valuable in online shopping. The present study reveals that product delivery risk and product quality risk have no significant effect on customers' intention to purchase and their actual purchase of fashion products. The findings give an idea to e-retailers especially those in the fashion industry that product delivery risk and product quality risk does not necessarily influence consumers' intention to purchase fashion product and eventually their actual purchase. Nonetheless, it is essential for e-retailers, shopping platform owners, and marketing managers to strive to maintain the trust that consumers have that fashion products purchased will be of good quality and be delivered safely. Despite this finding, privacy risk could influence Ghanaian consumers' intention to purchase and their actual purchase of fashion products. Thus, an e-retailer needs to ensure a well-managed and well-conducted online shopping platform that guarantees its users' safety.

Regarding, consumers perceived value for money, the current research reveals that perceived ease of use exhibit a significant positive influence on consumer intention to purchase fashion product but not on their actual purchase. The findings imply that if consumers believe that using a shopping platform will be less stressful and easy, then it will influence their intention to use the platform to purchase fashion products. As such, platform owners or e-retailers ought to ensure that they provide enough information about the fashion product they sell, ensure that their platform is user-friendly, effective customer services, effective tracking information systems, and others.

According to the study's findings, price differentials can influence consumers' intention to purchase, leading to their actual purchase of fashion products. The findings imply online consumers pay attention to the price of the fashion product when shopping. Accordingly, managers of online retailers need to ensure that they offer their products at reasonable prices. One way to attain this is by comparing their price to other e-retailers or shopping platforms that offer similar sales.

The current research further reveals that consumers' intention to purchase will eventually lead to an actual purchase. Purchase intention predicts the possibility that a customer will buy a fashion product from an online shopping platform. The findings imply that once online consumers intend to buy fashion products, they will proceed with the purchase. It would be relevant to managers of the online retailer to understand their customers better and develop appropriate measures to engage in building a solid relationship so that they (online consumers) will be loyal to their business.

\section{Limitation and Future Studies}

The study sought to determine how perceived risk and perceived value for money influence Ghanaian online consumers' intention to purchase and actual 
purchase fashion products. This study is however coupled with some limitations. The study focused on only Ghanaian consumers hence the could not be generalized to other jurisdictions especially outside sub-Saharan Africa. Future studies could replicate the results in other jurisdictions across the globe. Several factors can influence consumer purchase decisions in an online shopping platform. Hence, we suggest future studies to examine additional factors that can influence consumer behavior when shopping online. Additionally, future studies should control other factors such as age, gender, shopping experience, shopping frequency, amongst others that may affect consumer shopping behavior. Again, cross-sectional data are employed to assess the research hypotheses. Future research could use a longitudinal study to help extend an understanding of the causal relationships between the constructs.

\section{Conflicts of Interest}

The authors declare no conflicts of interest regarding the publication of this paper.

\section{References}

Adnan, H. (2014). An Analysis of the Factors Affecting Online Purchasing Behavior of Pakistani Consumers. International Journal of Marketing Studies, 6, 133. https://doi.org/10.5539/ijms.v6n5p133

Agmeka, F., Wathoni, R. N., \& Santoso, A. S. (2019). The Influence of Discount Framing towards Brand Reputation and Brand Image on Purchase Intention and Actual Behaviour in e-Commerce. Procedia Computer Science, 161, 851-858.

https://doi.org/10.1016/j.procs.2019.11.192

Ailawadi, K. L., Neslin, S. A., \& Gedenk, K. (2001). Pursuing the Value-Conscious Consumer: Store Brands versus National Brand Promotions. Journal of Marketing, 65, 71-89. https://doi.org/10.1509/jmkg.65.1.71.18132

Ali, A., \& Bhasin, J. (2019). Understanding Customer Repurchase Intention in E-commerce: Role of Perceived Price, Delivery Quality, and Perceived Value. Jindal Journal of Business Research, 8, 142-157. https://doi.org/10.1177/2278682119850275

Amponsah, R. K., \& Antwi, S. (2021). Consumers Attraction to Purchase Online: Website Quality as a Major Influencing Factor. Open Journal of Business and Management, 9, 1133-1150. https://doi.org/10.4236/ojbm.2021.93061

Antwi, S. (2021). "I Just Like This e-Retailer": Understanding Online Consumers Repurchase Intention from Relationship Quality Perspective. Journal of Retailing and Consumer Services, 61, Article ID: 102568. https://doi.org/10.1016/j.jretconser.2021.102568

Antwi, S., \& Amponsah, R. K. (2021). Repurchase Intention among Ghanaian Online Consumers: Perceived Shopping Value Approach. European Journal of Business and Management, 13, 1-10. https://doi.org/10.7176/ejbm/13-8-01

Antwi, S., Ameyaw, M. A., \& Adamu, M. M. (2020). What Drives Online Shopping among Tertiary Students in Ghana: The Role of Attitude And Subjective Norm. Journal of Applied Management and Advanced Research, 2, 51-61. https://doi.org/10.34047/JAMAR.2020.v02i01.005

Antwi, S., Bei, W., \& Ameyaw, M. A. (2021). Investigating the Moderating Role of Social Support in Online Shopping Intentions. Journal of Marketing and Consumer Research, 
78, 27-34. https://doi.org/10.7176/JMCR/78-04

Ariff, M. S. M., Yan, N. S., Zakuan, N., Bahari, A. Z., \& Jusoh, A. (2013). Web-Based Factors Affecting online Purchasing Behaviour. IOP Conference Series: Materials Science and Engineering, 46, Article ID: 012038. https://doi.org/10.1088/1757-899X/46/1/012038

Arora, N., \& Rahul, M. (2018). The Role of Perceived Risk in Influencing Online Shopping Attitude among Women in India. International Journal of Public Sector Performance Management, 4, 98. https://doi.org/10.1504/IJPSPM.2018.088697

Bhatnagar, A., \& Ghose, S. (2004). Segmenting Consumers Based on the Benefits and Risks of Internet Shopping. Journal of Business Research, 57, 1352-1360.

https://doi.org/10.1016/S0148-2963(03)00067-5

Bhatti, A., \& Ur Rehman, S. (2020). Perceived Benefits and Perceived Risks Effect on Online Shopping Behavior with the Mediating Role of Consumer Purchase Intention in Pakistan. International Journal of Management Studies, 26, 33-54. https://doi.org/10.32890/ijms.26.1.2019.10512

Boateng, R., Heeks, R., Molla, A., \& Hinson, R. (2011). Advancing E-Commerce beyond Readiness in a Developing Country: Experiences of Ghanaian Firms. Journal of Electronic Commerce in Organizations, 9, 1-16. https://doi.org/10.4018/jeco.2011010101

Bolton, L. E., Warlop, L., \& Alba, J. W. (2003). Consumer Perceptions of Price (Un)Fairness. Journal of Consumer Research, 29, 474-491.

https://doi.org/10.1086/346244

Broekhuizen, T. L. J., \& Huizingh, E. (2006). Investigating the Effect of Consumer Traits on the Relative Importance of TAM Constructs in an e-Commerce Context. Proceedings from the ICEB EBRF Conference, Tampere, Finland, November 28-December 2, 2006, 29. https://aisel.aisnet.org/cgi/viewcontent.cgi?article=1036\&context=iceb2006

Cha, J. (2011). Exploring the Internet as a Unique Shopping Channel to Sell both Real and Virtual Items: A Comparison of Factors Affecting Purchase Intention and Consumer Characteristics. Journal of Electronic Commerce Research, 12, 115.

https://citeseerx.ist.psu.edu/viewdoc/download?doi=10.1.1.466.5410\&rep=rep1\&type= pdf

Chang, K. C., Hsu, C. L., Chen, M. C., \& Kuo, N. Te. (2019). How a Branded Website Creates Customer Purchase Intentions. Total Quality Management and Business EXcellence, 30, 422-446. https://doi.org/10.1080/14783363.2017.1308819

Chen, H., Beaudoin, C. E., \& Hong, T. (2017). Securing Online Privacy: An Empirical Test on Internet Scam Victimization, Online Privacy Concerns, and Privacy Protection Behaviors. Computers in Human Behavior, 70, 291-302. https://doi.org/10.1016/j.chb.2017.01.003

Chen, Y., Yan, X., \& Fan, W. (2015). Examining the Effects of Decomposed Perceived Risk on Consumer Online Shopping Behavior: A Field Study in China. Engineering Economics, 26, 315-326. https://doi.org/10.5755/j01.ee.26.3.8420

Chiu, Y. B., Lin, C. P., \& Tang, L. L. (2005). Gender Differs: Assessing a Model of Online Purchase Intentions in e-Tail Service. International Journal of Service Industry Management, 16, 416-435. https://doi.org/10.1108/09564230510625741

Cho, E., \& Son, J. (2019). The Effect of Social Connectedness on Consumer Adoption of Social Commerce in Apparel Shopping. Fashion and Textiles, 6, 14. https://doi.org/10.1186/s40691-019-0171-7

Cho, Y. C., \& Sagynov, E. (2015). Exploring Factors That Affect Usefulness, Ease of Use, Trust, and Purchase Intention in the Online Environment. International Journal of Management \& Information Systems (IJMIS), 19, 21. 
https://doi.org/10.19030/ijmis.v19i1.9086

Coase, R. (1937). The Nature of the Firm. In The Economic Nature of the Firm: A Reader (pp. 89-104). Cambridge University Press. https://doi.org/10.1111/j.1468-0335.1937.tb00002.x

Cochran, W. G. (1977). Sampling Techniques (3rd ed.). John Wiley \& Sons. https://www.wiley.com/en-us/Sampling+Techniques\%2C+3rd+Edition-p-97804711624 $\underline{07}$

Cohen, J. (1992). Quantitative Methods in Psychology: A Power Primer. Psychological Bulletin, 112, 1155-1159. https://doi.org/10.1037/0033-2909.112.1.155

Davis, F. D. (1989). Perceived Usefulness, Perceived Ease of Use, and User Acceptance of Information Technology. MIS Quarterly: Management Information Systems, 13, 319-339. https://doi.org/10.2307/249008

Davis, F. D. (1993). User Acceptance of Information Technology: System Characteristics, User Perceptions and Behavioral Impacts. International Journal of Man-Machine Studies, 38, 475-487. https://doi.org/10.1006/imms.1993.1022

de Kerviler, G., Demoulin, N. T. M., \& Zidda, P. (2016). Adoption of In-Store Mobile Payment: Are Perceived Risk and Convenience the Only Drivers? Journal of Retailing and Consumer Services, 31, 334-344. https://doi.org/10.1016/j.jretconser.2016.04.011

Edenbrandt, A. K., \& Smed, S. (2018). Exploring the Correlation between Self-Reported Preferences and Actual Purchases of Nutrition Labeled Products. Food Policy, 77, 71-80. https://doi.org/10.1016/j.foodpol.2018.04.007

eMarketer (2019). Global Retail e-Commerce Market Size 2014-2023. https://www.statista.com/statistics/379046/worldwide-retail-e-commerce-sales

Fornell, C., \& Larcker, D. F. (1981). Evaluating Structural Equation Models with Unobservable Variables and Measurement Error. Journal of Marketing Research, 18, 39-50. https://doi.org/10.1177/002224378101800104

Forsythe, S., Liu, C., Shannon, D., \& Gardner, L. C. (2006). Development of a Scale to Measure the Perceived Benefits and Risks of Online Shopping. Journal of Interactive Marketing, 20, 55-75. https://doi.org/10.1002/dir.20061

Gao, L., \& Bai, X. (2014). A Unified Perspective on the Factors Influencing Consumer Acceptance of Internet of Things Technology. Asia Pacific Journal of Marketing and Logistics, 26, 211-231. https://doi.org/10.1108/APJML-06-2013-0061

Hair, J. F., Hult, G. T. M., Ringle, C. M., \& Sarstedt, M. (2016). A Primer on Partial Least Squares Structural Equation Modeling (PLS-SEM) (2nd ed.). Sage Publications. https://us.sagepub.com/en-us/nam/a-primer-on-partial-least-squares-structural-equati on-modeling-pls-sem/book244583

Hair, J. F., Ringle, C. M., \& Sarstedt, M. (2011). PLS-SEM: Indeed a Silver Bullet. Journal of Marketing Theory and Practice, 19, 139-152. https://doi.org/10.2753/MTP1069-6679190202

Hajli, N. (2015). Social Commerce Constructs and Consumer's Intention to Buy. International Journal of Information Management, 35, 183-191. https://doi.org/10.1016/j.ijinfomgt.2014.12.005

Hajli, N., Sims, J., Zadeh, A. H., \& Richard, M. O. (2017). A Social Commerce Investigation of the Role of Trust in a Social Networking Site on Purchase Intentions. Journal of Business Research, 71, 133-141. https://doi.org/10.1016/j.jbusres.2016.10.004

Henseler, J., Ringle, C. M., \& Sarstedt, M. (2015). A New Criterion for Assessing Discriminant Validity in Variance-Based Structural Equation Modeling. Journal of the Academy of Marketing Science, 43, 115-135. 
https://doi.org/10.1007/s11747-014-0403-8

Kim, E. Y., \& Kim, Y. (2004). Predicting Online Purchase Intentions for Clothing Products. European Journal of Marketing, 38, 883-897. https://doi.org/10.1108/03090560410539302

Kim, H. W., Xu, Y., \& Gupta, S. (2012). Which Is More Important in Internet Shopping, Perceived Price or Trust? Electronic Commerce Research and Applications, 11, 241-252. https://doi.org/10.1016/j.elerap.2011.06.003

Kim, L. H., Kim, D. J., \& Leong, J. K. (2005). The Effect of Perceived Risk on Purchase Intention in Purchasing Airline Tickets Online. Journal of Hospitality and Leisure Marketing, 13, 33-53. https://doi.org/10.1300/J150v13n02_04

Koyuncu, C., \& Bhattacharya, G. (2004). The Impacts of Quickness, Price, Payment Risk, and Delivery Issues on On-Line Shopping. Journal of Socio-Economics, 33, 241-251. https://doi.org/10.1016/j.socec.2003.12.011

Lee, J., \& Lee, J. N. (2015). How Purchase Intention Consummates Purchase Behaviour: The Stochastic Nature of Product Valuation in Electronic Commerce. Behaviour and Information Technology, 34, 57-68. https://doi.org/10.1080/0144929X.2013.853837

Liao, T. H., \& Keng, C. J. (2013). Online Shopping Delivery Delay: Finding a Psychological Recovery Strategy by Online Consumer Experiences. Computers in Human Behavior, 29, 1849-1861. https://doi.org/10.1016/j.chb.2013.03.004

Lin, P. J., Jones, E., \& Westwood, S. (2009). Perceived Risk and Risk-Relievers in Online Travel Purchase Intentions. Journal of Hospitality and Leisure Marketing, 18, 782-810. https://doi.org/10.1080/19368620903235803

Liu, Y., Segev, S., \& Villar, M. E. (2017). Comparing Two Mechanisms for Green Consumption: Cognitive-Affect Behavior vs Theory of Reasoned Action. Journal of Consumer Marketing, 34, 442-454. https://doi.org/10.1108/JCM-01-2016-1688

Maia, C. R., Lunardi, G. L., Dolci, D., \& D’Avila, L. C. (2019). Competitive Price and Trust as Determinants of Purchase Intention in Social Commerce. Brazilian Administration Review, 16, e190074. https://doi.org/10.1590/1807-7692bar2019190074

Millan, E., \& Reynolds, J. (2014). Self-Construals, Symbolic and Hedonic Preferences, and Actual Purchase Behavior. Journal of Retailing and Consumer Services, 21, 550-560. https://doi.org/10.1016/j.jretconser.2014.03.012

Mintah, S. C. (2018). Consumer Perceived Risk and Online Shopping in Ghana: The Moderating Role of Electronic-Word of Mouth. University of Ghana. http://ugspace.ug.edu.gh/handle/123456789/31162

Nunnally, J. C., \& Bernstein, I. H. (1994). Psychometric Theory(3rd ed.). McGraw-Hill. https://www.worldcat.org/title/psychometric-theory/oclc/28221417

Omar, P. D. O. E. (2005). UK Consumers' Adoption of the Internet for Grocery Shopping. AU Journal of Management, 3, 11-18. https://www.aujm.au.edu/index.php/aujm/article/view/88

Paluch, S., \& Wunderlich, N. V. (2016). Contrasting Risk Perceptions of Technology-Based Service Innovations in Inter-Organizational Settings. Journal of Business Research, 69, 2424-2431. https://doi.org/10.1016/j.jbusres.2016.01.012

Park, S., \& Tussyadiah, I. P. (2017). Multidimensional Facets of Perceived Risk in Mobile Travel Booking. Journal of Travel Research, 56, 854-867. https://doi.org/10.1177/0047287516675062

Pavlou, P. A. (2003). Consumer Acceptance of Electronic Commerce: Integrating Trust and Risk with the Technology Acceptance Model. International Journal of Electronic Commerce, 7, 101-134. https://doi.org/10.1080/10864415.2003.11044275 
Peng, L., \& Liang, S. (2013). The Effects of Consumer Perceived Value on Purchase Intention in e-Commerce Platform: A Time-Limited Promotion Perspective. Proceedings of the Thirteen International Conference on Electronic Business, Nanyang Executive Centre, 1-4 December 2013, 1-4, 56. http://eli.johogo.com/ICEB-JJAW-2013/2-3.pdf

Rehman, S. U., Bhatti, A., Mohamed, R., \& Ayoup, H. (2019). The Moderating Role of Trust and Commitment between Consumer Purchase Intention and Online Shopping Behavior in the Context of Pakistan. Journal of Global Entrepreneurship Research, 9, 43. https://doi.org/10.1186/s40497-019-0166-2

Ringle, C. M., Wende, S., \& Becker, J.-M. (2015). SmartPLS 3. Boenningstedt. SmartPLS $\mathrm{GmbH}$. http://www.smartpls.com

Setiawan, E. B., Kartini, D., Afiff, F., \& Rufaidah, P. (2016). Impact of Price Fairness on Brand Image and Purchase Intention for Low Cost Car in Indonesia. International Journal of Economics, Commerce and Management, 4, 300-308.

https://p3m.itltrisakti.ac.id/wp-content/uploads/2019/03/Download-File-02.pdf

Sheehan, D., Hardesty, D. M., Ziegler, A. H., \& Chen, H. (Allan). (2019). Consumer Reactions to Price Discounts across Online Shopping Experiences. Journal of Retailing and Consumer Services, 51, 129-138. https://doi.org/10.1016/j.jretconser.2019.06.001

Sinha, P., \& Singh, S. (2017). Comparing Risks and Benefits for the Value Enhancement of Online Purchases. Gadjah Mada International Journal of Business, 19, 307-326. https://search.informit.org/doi/abs/10.3316/informit.317778082844063 https://doi.org/10.22146/gamaijb.10512

Spake, D. F., Zachary Finney, R., \& Joseph, M. (2011). Experience, Comfort, and Privacy Concerns: Antecedents of Online Spending. Journal of Research in Interactive Marketing, 5, 5-28. https://doi.org/10.1108/17505931111121507

Spiller, S. A., \& Ariely, D. (2014). The Perceived Value of Money Depends on Irrelevant Uses. https://marketing.wharton.upenn.edu/wp-content/uploads/2016/10/SpillerValueOfMo ney.pdf

Statista (2020). Ghana 2020: Statista Country Report. Statista. https://www.statista.com/study/48439/ghana

Teo, T. S. H., \& Yu, Y. (2005). Online Buying Behavior: A Transaction Cost Economics Perspective. Omega, 33, 451-465. https://doi.org/10.1016/j.omega.2004.06.002

Ventre, I., \& Kolbe, D. (2020). The Impact of Perceived Usefulness of Online Reviews, Trust and Perceived Risk on Online Purchase Intention in Emerging Markets: A Mexican Perspective. Journal of International Consumer Marketing, 32, 287-299. https://doi.org/10.1080/08961530.2020.1712293

Verhagen, T., Meents, S., \& Tan, Y. H. (2006). Perceived Risk and Trust Associated with Purchasing at Electronic Marketplaces. European Journal of Information Systems, 15, 542-555. https://doi.org/10.1057/palgrave.ejis.3000644

Wagner Mainardes, E., de Almeida, C. M., \& de-Oliveira, M. (2019). e-Commerce: An Analysis of the Factors That Antecede Purchase Intentions in an Emerging Market. Journal of International Consumer Marketing, 31, 447-468. https://doi.org/10.1080/08961530.2019.1605643

Wee, C. S., Ariff, M. S. B. M., Zakuan, N., Tajudin, M. N. M., Ismail, K., \& Ishak, N. (2014). Consumers Perception, Purchase Intention and Actual Purchase Behavior of Organic Food Products. Review of Integrative Business and Economics Research, 3, 378. http://buscompress.com/uploads/3/4/9/8/34980536/riber_b14-173_378-397_.pdf

Wu, L. Y., Chen, K. Y., Chen, P. Y., \& Cheng, S. L. (2014). Perceived Value, Transaction Cost, and Repurchase-Intention in Online Shopping: A Relational Exchange Perspec- 
tive. Journal of Business Research, 67, 2768-2776.

https://doi.org/10.1016/j.jbusres.2012.09.007

Xia, L., Monroe, K. B., \& Cox, J. L. (2004). The Price Is Unfair! A Conceptual Framework of Price Fairness Perceptions. Journal of Marketing, 68, 1-15.

https://doi.org/10.1509/jmkg.68.4.1.42733

Yoshimaru, S., Sakamoto, D., Yazawa, T., \& Tsuda, K. (2018). Correlation Analysis between Customer's Behaviour on Website and Actual Purchase. Procedia Computer Science, 126, 1450-1456. https://doi.org/10.1016/j.procs.2018.08.117

Yu, T. W., \& Chen, T. J. (2018). Online Travel Insurance Purchase Intention: A Transaction Cost Perspective. Journal of Travel and Tourism Marketing, 35, 1175-1186. https://doi.org/10.1080/10548408.2018.1486781

Yu, W., Han, X., Ding, L., \& He, M. (2021). Organic Food Corporate Image and Customer Co-Developing Behavior: The Mediating Role of Consumer Trust and Purchase Intention. Journal of Retailing and Consumer Services, 59, Article ID: 102377. https://doi.org/10.1016/j.jretconser.2020.102377

Yuen, K. F., Wang, X., Wong, Y. D., \& Zhou, Q. (2018). The Effect of Sustainable Shipping Practices on Shippers' Loyalty: The Mediating Role of Perceived Value, Trust and Transaction Cost. Transportation Research Part E: Logistics and Transportation Review, 116, 123-135. https://doi.org/10.1016/j.tre.2018.06.002

Zaiț, A., \& Bertea, P. (2013). Privacy Risk-Not a Risk for Romanian Online Shoppers? Studia Ekonomiczne, 151, 57-67.

http://cejsh.icm.edu.pl/cejsh/element/bwmeta1.element.desklight-6aa3edf7-80d4-46deacd8-814d5a0e524f

Zeithaml, V. A. (1988). Consumer Perceptions of Price, Quality, and Value: A Means-End Model and Synthesis of Evidence. Journal of Marketing, 52, 2-22. https://doi.org/10.1177/002224298805200302

Zendehdel, M., Paim, L. H., \& Delafrooz, N. (2016). The Moderating Effect of Culture on the Construct Factor of Perceived Risk towards Online Shopping Behaviour. Cogent Business \& Management, 3, Article ID: 1223390. https://doi.org/10.1080/23311975.2016.1223390

Zhang, M., Qin, F., Wang, G. A., \& Luo, C. (2020). The Impact of Live Video Streaming on Online Purchase Intention. Service Industries Journal, 40, 656-681.

https://doi.org/10.1080/02642069.2019.1576642 


\section{Appendix}

\section{Research Survey}

This study aimed to explore the effect of perceived risks and perceived value for money on shopping for fashion products online among Ghanaian consumers. You are therefore invited to participate in this survey. Any information provided for this study will be treated with utmost confidentiality and anonymity. This questionnaire is designed for academic purposes only.

\section{Section A}

\section{DI1. Gender}
1) Male
2) Female

DI2. Age (in years):
1) Below 20
2) 20 - 30
3) $31-40$
4) Above 40

DI3. Online Shopping Experience (in years)
1) Below 1
2) $1-3$
3) $4-6$
4) $7-10$
5) Above 10

DI4. Level of Education
1) Senior High School
2) Diploma
3) Degree
4) Masters
5) $\mathrm{PhD}$

DI5. Occupation
1) Public Sector-Employed
2) Private Sector-Employed

\section{Section B}

Rate the extent to which the following statements in the matrix represented below reflect you. Use a scale of 1 to 5 ( $1=$ Strongly Disagree, $2=$ Disagree, $3=$ Neutral/Uncertain, $4=$ Agree, $5=$ Strongly Agree). How much do you agree with each statement about you as you generally are now, not as you wish to be in the future?

Tick as applicable.

\section{Product Quality Risk (PQR)}

PQR1: I am worried that the quality of the fashion product may not be acceptable.

PQ2R: I am worried that the fashion product performance may not be consistent with my expectation.

PQR3: I am worried that the size of the fashion product may not be appropriate.

PQR4: I am worried that it will be difficult for me to compare the quality to other similar fashion products.

PQR5: I am worried that the fashion product may be false.

\section{Product Delivery Risk (PDR)}

PDR1: I am worried that the fashion product may be delivered to a wrong address.

PDR2: I am worried that the fashion product may be damaged in transit.

PDR3: I am worried that the fashion product could be lost in transit.

PDR4: I am worried that after-delivery services may not be guaranteed.

PDR5: I am worried that I must pay for handling and other hidden fees. 


\section{Privacy Risk (PRR)}

PRR1: I am worried that shopping for fashion products on an online shopping platform may jeopardize my privacy.

PRR2: I am worried that my payment information may be leaked.

PRR3: I feel safer shopping for fashion products on an online shopping platform than on the traditional store.

PRR4: I feel that online retailers may track my shopping habit and history without my knowledge.

PRR5: I feel the online store could leak out my personal data.

Perceived Ease of Use (PEU)

PEU1: Shopping for fashion products online does not require a lot of mental effort.

PEU2: It is easy to use online shopping platforms to buy fashion products.

PEU3: My interaction with shopping platforms for fashion product is clear and understandable.

PEU4: The use of an online shopping platform to shop for fashion products allow me to shop the way I want to.

PEU5: The use of an online shopping platform is easy for me to become skillful.

\section{Price Differentials (PDF)}

PDF1: Online shopping platforms provide attractive and valuable fashion products.

PDF2: Online shopping platforms offer reasonable and satisfactory fashion products.

PDF3: I can buy fashion products at a lower price from an online shopping platform than a traditional store.

PDS4: Fashion products purchased online are value for money.

PDS5: Fashion products purchased online are worth the money paid.

Transaction Cost (TRC)

TRC1: I spend a lot of effort getting fashion information that would be helpful in the decision-making of online purchases.

TRC2: Usually, there is so much to do that I wish I had more time to look for information before buying a fashion product online.

TRC3: I spend a lot of effort contacting the online store to check whether the fashion products I ordered are processed.

TRC4: I spend a lot of time monitoring whether the fashion products I ordered are processed.

TRC5: I incur charges to make changes to orders that have been sent to online stores.

\section{Intention to Purchase (IP)}

IP1: I have the intention to shop fashion product from an online shopping platform.

IP2: I plan to shop fashion products on regular basics from an online shop- 
ping platform.

IP3: I will recommend my friends and family to buy fashion products from an online shopping platform.

IP4: I intend to shop fashion products online because it is compatible with my lifestyle.

IP5: I intend to shop for fashion product online as I do not have to leave home for shopping.

IP6: I intend to shop fashion products from an online shopping platform because it is safe to use.

\section{Actual Purchase (AP)}

AP1: I often shop fashion products from online shopping platforms.

AP2: I often shop fashion products on regular basics from an online shopping platform.

AP3: I often recommend my friends and family to buy fashion products from an online shopping platform.

AP4: I often find shopping for fashion products online to be compatible with my lifestyle.

AP5: I often buy fashion products from online shopping platforms because they are more convenient.

AP6: I often buy fashion products from online shopping platform because it is safe to use. 